\title{
Análise SWOT como ferramenta para diagnosticar o potencial turístico da Comunidade Ponta de Pedras, Santarém (PA)
}

Objetiva-se, através desta pesquisa, diagnosticar e analisar a situação atual do potencial turístico da comunidade Ponta de Pedras em Santarém (PA) através do método empresarial de análise SWOT. A comunidade está localizada a aproximadamente $35 \mathrm{~km}$ do centro do município de Santarém, oeste do estado do Pará. O acesso até a praia presente na comunidade acontece de duas formas: via terrestre, através da Rodovia Everaldo Martins $23 \mathrm{~km}$ e mais $12 \mathrm{Km}$ em estrada sem pavimentação, e via fluvial, pelo Rio Tapajós. Utilizou-se neste estudo: pesquisa de campo, pesquisa bibliográfica e documental. Para a elaboração da matriz SWOT, foi necessário o estabelecimento dos parâmetros observados na comunidade durante a realização da pesquisa, para posterior análise entre forças, oportunidades, fraquezas e ameaças. No eixo horizontal, posicionaram-se as forças e fraquezas; já no eixo vertical, as oportunidades e ameaças. A partir daí, houve a correlação entre as áreas (sociais, ambientais e econômicas). Em relação aos pontos negativos, verificou-se a falta de requisitos básicos, como saneamento, saúde e infraestrutura entre outros. Com relação à análise de SWOT, esses requisitos são precários ou tampouco insistentes. Foi constatada a falta de planejamento e o descaso em relação ao investimento para o turismo na comunidade. Após a realização da análise de SWOT, foi possível traçar estratégias que possibilitam promover o desenvolvimento local de forma sustentável e novas rotas turísticas para que possa desenvolver o turismo e a economia da comunidade. Também subsidiar o suporte para implementação de programas de conservação do meio ambiente para um turismo sustentável.

Palavras-chave: Análise SWOT; Desenvolvimento turístico; Turismo sustentável.

\section{SWOT analysis as a tool to diagnose the tourism potential of Ponta de Pedras Community, Santarém (PA)}

\begin{abstract}
The objective of this research is to diagnose and analyze the current situation of the tourism potential of the Ponta de Pedras community in Santarém (PA) through the business method of SWOT analysis. The community is located approximately $35 \mathrm{~km}$ from the center of the municipality of Santarém, west of the state of Pará. The access to the beach in the community happens in two ways: by land, through the Everaldo Martins Highway $23 \mathrm{~km}$ and $12 \mathrm{~km}$ on unpaved road, and waterway, by the Tapajós River. We used in this study: field research, bibliographic and documentary research. For the elaboration of the SWOT matrix, it was necessary to establish the parameters observed in the community during the research, for further analysis between strengths, opportunities, weaknesses and threats. On the horizontal axis, strengths and weaknesses were positioned; on the vertical axis, opportunities and threats. From there, there was the correlation between the areas (social, environmental and economic). Regarding the negative points, there was a lack of basic requirements such as sanitation, health and infrastructure, among others. Regarding SWOT analysis, these requirements are precarious or not insistent. There was a lack of planning and disregard for investment in tourism in the community. After the SWOT analysis, it was possible to outline strategies that make it possible to promote sustainable local development and new tourist routes so that it can develop tourism and the community economy. Also subsidize support for implementing environmental conservation programs for sustainable tourism.
\end{abstract}

Keywords: SWOT analysis; Tourism development; Sustainable tourism.

Topic: Desenvolvimento, Sustentabilidade e Meio Ambiente

Reviewed anonymously in the process of blind peer.

Sabrina Santos da Costa (iD)

Universidade Federal do Oeste do Pará, Brasil http://lattes.cnpq.br/5987680798801956 http://orcid.org/0000-0002-0661-8173 sabrina.costt@gmail.com

Tatiane Almeida Lemos

Universidade Federal do Oeste do Pará, Brasil http://lattes.cnpq.br/6686564498403621

http://orcid.org/0000-0002-4495-3618

tati_5almeida@hotmail.com

Diego Patrick Fróes Campos (iD)

Universidade Federal do Oeste do Pará, Brasil

http://lattes.cnpq.br/2662617598318134

http://orcid.org/0000-0003-0262-8750

diegofroes.campos@gmail.com

6

DOI: 10.6008/CBPC2179-6858.2018.006.0023
Received: 20/08/2018

Approved: 26/08/2018
Josciane Carneiro Oliveira (iD)

Universidade Federal do Oeste do Pará, Brasil

http://lattes.cnpq.br/1834237161872689

http://orcid.org/0000-0002-6165-3342

joscianecarneiro12@gmail.com

Quêzia Leandro de Moura Guerreiro

Universidade Federal do Oeste do Pará, Brasil

http://lattes.cnpq.br/2392493799166491

http://orcid.org/0000-0002-4382-1250

queziamoura@hotmail.com
Referencing this:

COSTA, S. S.; LEMOS, T. A.; CAMPOS, D. P. F.; OLIVEIRA, J. C.; GUERREIRO, Q. L. M.. Análise SWOT como ferramenta para diagnosticar o potencial turístico da Comunidade Ponta de Pedras, Santarém (PA). Revista Ibero-Americana de Ciências Ambientais, v.9, n.6, p.230-240, 2018. DOI: http://doi.org/10.6008/CBPC21796858.2018 .006 .0023 


\section{INTRODUÇÃO}

Nos últimos anos, o turismo tem apresentado crescimento extremamente veloz e significativo nas mais diversas regiões do mundo, com índices em torno de 1,322 bilhão de viajantes internacionais, o que significa um aumento de 7\% com relação a 2016, tornando-se assim o melhor resultado em sete anos (BRASIL, 2018). O setor turístico é responsável por 292 milhões de empregos e proporciona desenvolvimento econômico, assim como, a ampliação do mercado de trabalho e geração de mudanças no quadro social de algumas cidades (LIMA, 2006).

De acordo com a OMT (2014) "o turismo compreende as atividades que as pessoas realizam durante suas viagens e estadas em lugares diferentes ao seu entorno habitual, por um período consecutivo inferior a um ano, com finalidade de lazer, negócio ou outras". Partindo dessa perspectiva, uma atividade turística nada mais é que um deslocamento por um período que fuja de lugares que fazem parte da rotina, com múltiplos desígnios.

A atividade turística pode ser compreendida como um conjunto de elementos interrelacionados que evoluem de forma dinâmica. Sobre o conceito de atividade turística, Braga (2013) destaca quatro elementos básicos: a demanda, formada por um conjunto de consumidores de bens e serviços públicos; a oferta, composta pelo conjunto de produtos, serviços e organizações envolvidos ativamente na experiência turística; o espaço geográfico, base física na qual se dá o encontro ou contato entre a oferta e a demanda e em que se situa a população residente, que se não é em si mesma um elemento turístico, é considerada importante fator de coesão ou desagregação; os operadores do mercado, empresas ou organismos cuja principal função é facilitar a interação entre a oferta e a demanda, as agências de viagem, companhias de transporte regular de órgãos públicos e privados que organizam e promovem o turismo.

O turismo, como qualquer outra atividade, apresenta aspectos positivos e negativos que devem ser avaliados frequentemente devido à sua intensa dinâmica e capacidade de estar em constante mutação. Um destino turístico pode ter um boom de procura de um momento para o outro, mas também pode entrar em decadência com a mesma velocidade com que cresceu. Nesse aspecto, o turismo, mais que outra atividade, é bastante dependente do planejamento e do contínuo monitoramento do espaço geográfico onde se desenvolve a atividade (DIAS, 2008; BARRETO, 2009; CHAGAS et al., 2013).

A análise SWOT estuda a competitividade de uma organização segundo quatro variáveis: Strengths (Forças), Weaknesses (Fraquezas), Oportunities (Oportunidades) e Threats (Ameaças) (RODRIGUES, 2005). Para Andion et al. (2002), "através da análise dos pontos fortes e fracos, os gestores e suas equipes poderão determinar com mais clareza as prioridades em termos de ameaças e oportunidades existentes no ambiente externo".

Corporações e planejadores do turismo têm utilizado com bastante aceitação a análise SWOT. Assim, esta metodologia torna-se uma ferramenta ideal no processo de gestão e monitoramento do turismo de uma determinada localidade, assim como também permite diagnosticar as potencialidades turísticas existentes no local e ajustes necessários nas falhas para que o setor turístico possa ter retorno (DANTAS et al., 2008). 
Antes da utilização da ferramenta SWOT, Ancín (2006) afirma que é necessário traçar uma análise da situação, ou seja, estabelecer um diagnóstico para que se tenha um cenário ideal de aplicação. No que tange ao turismo, a análise SWOT torna-se importante, pois permitirá que o planejador demarque as principais linhas de atuação e melhore sua colocação frente ao mercado turístico além de verificar as políticas públicas que orientam ações prévias à implantação da atividade turística e seu processo de organização e planejamento (BIGNÉ et al., 2000; ABREU et al., 2014).

O diagnóstico turístico de uma determinada localidade, associada à aplicação de indicadores na matriz SWOT, cria um cenário que orienta para a melhoria da gestão do turismo do ambiente em questão. Silva et al. (2016), em seu trabalho, utilizando este tipo de análise, afirma que a partir das experiências diagnosticadas agrega-se valor ao produto turístico tais como "cultural, social e ecológico", significando-se assim com uma forma não linear de fortalecimento do potencial da comunidade para o turismo.

Ponta de Pedras, um dos principais pontos turísticos da região oeste do estado do Pará, é uma comunidade localizada a $23 \mathrm{~km}$ do município de Santarém, distando $700 \mathrm{~km}$ da capital Belém. A população local está organizada para o atendimento da culinária regional a base de peixes, carne de gado e frango, além da combinação dos ambientes da praia extensa com o afloramento de pedras, que faz desta área uma das mais bonitas paisagens da orla do Rio Tapajós. A população residente na área é composta, em sua maioria, por remanescentes do período de produção da borracha na região (MARIANI et al., 2008).

A atividade turística desta área é um fator importante para o desenvolvimento da comunidade e precisa ser planejada a fim de garantir os princípios da sustentabilidade. Objetiva-se através desta pesquisa diagnosticar e analisar a situação atual do potencial turístico da comunidade Ponta de Pedras em Santarém, através do método empresarial de análise SWOT.

\section{MATERIAIS E MÉTODOS}

\section{Caracterização da área de estudo}

A comunidade Ponta de Pedras está à margem do Rio Tapajós e localizada a aproximadamente $35 \mathrm{~km}$ do centro do município de Santarém, oeste do estado do Pará (figura 1). A vegetação predominante é a floresta tropical, típica do Bioma Amazônia, com exceções de savanas amazônicas situadas ao extremo nordeste da área de estudo (FEITOSA et al., 2012). A região é caracterizada por um gradiente de uso da terra, com áreas alteradas, incluindo florestas secundárias, recobertas após o desmatamento (PUTZ et al., 2010). O clima é predominantemente quente e úmido, com temperatura média anual oscilando entre $25^{\circ}$ e $27^{\circ} \mathrm{C}$. A umidade relativa média do ar varia entre 80 e 90\%, e a precipitação pluvial anual oscila entre 1.800 e $2.800 \mathrm{~mm}$, com alternância de chuvas abundantes, no período de janeiro a julho, e curtos períodos de estiagem entre os meses de agosto a dezembro (EMBRAPA, 2014).

O acesso até a praia da comunidade Ponta de Pedras acontece através de via terrestre, pela Rodovia Everaldo Martins, a qual possui $23 \mathrm{~km}$ percorridos em estrada asfaltada e mais $12 \mathrm{~km}$ em estrada sem pavimentação, e por acesso fluvial. As águas do rio Tapajós são classificadas como claras, o mais transparente entre os tipos de rios da Amazônia, permitindo a entrada de luz até níveis mais profundos e possuindo 
tonalidade esverdeada (PEREIRA, 2007). O rio Tapajós estende-se desde a confluência de seus formadores, Teles Pires e Juruena, na tríplice divisa entre os estados do Pará, Amazonas e Mato Grosso, até a sua foz no rio Amazonas, próximo a Santarém. Sua extensão é de aproximadamente $851 \mathrm{~km}$, compreendendo, em relação às condições naturais de navegabilidade, distintamente o baixo e o médio Tapajós (EMBRAPA, 2010).

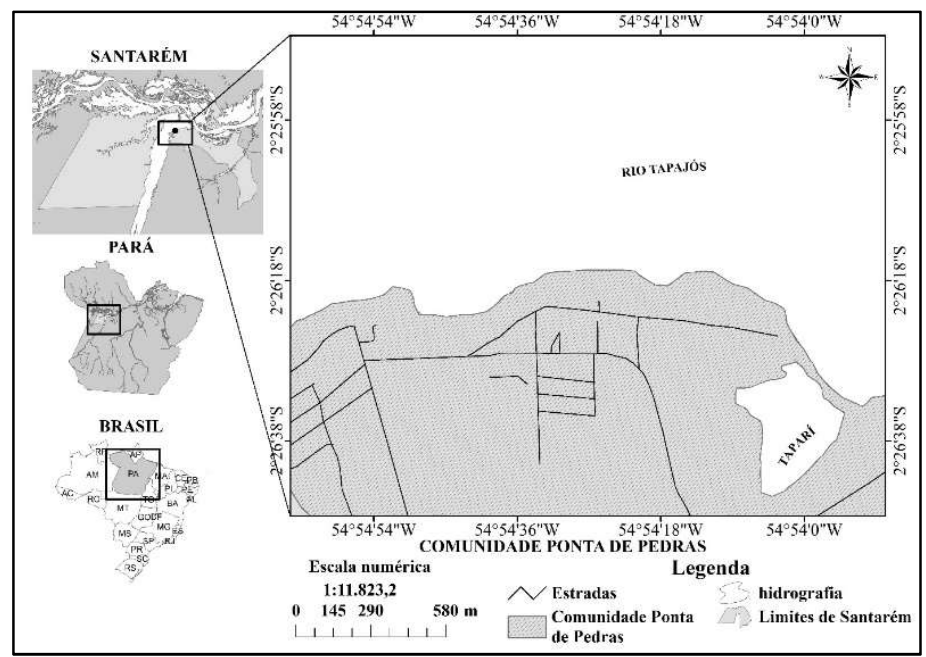

Figura 1: Localização da Comunidade Ponta de Pedras, município de Santarém, estado do Pará.

\section{Tipo de pesquisa e análise SWOT}

Para este estudo, usou-se a pesquisa de campo, realizada através de observações presenciais no mês de janeiro de 2018 e entrevistas semiestruturadas com moradores e turistas. Para a pesquisa documental, foram consultados documentos gerais disponibilizados por membros da comunidade e a pesquisa bibliográfica. Utilizou-se o método indutivo de pesquisa para conhecer as condições e realidades da praia, para então, desenvolver ideias e métodos para o desenvolvimento do turismo no local. Segundo Parra Filho et al. (2003), "o método indutivo vai permitir, a partir de observações, inferir condições e situações gerais e esperadas". Partindo desse princípio, desenvolveu-se o diagnóstico turístico local utilizando a análise do ambiente com base na matriz de análise do método SWOT (figura 2).

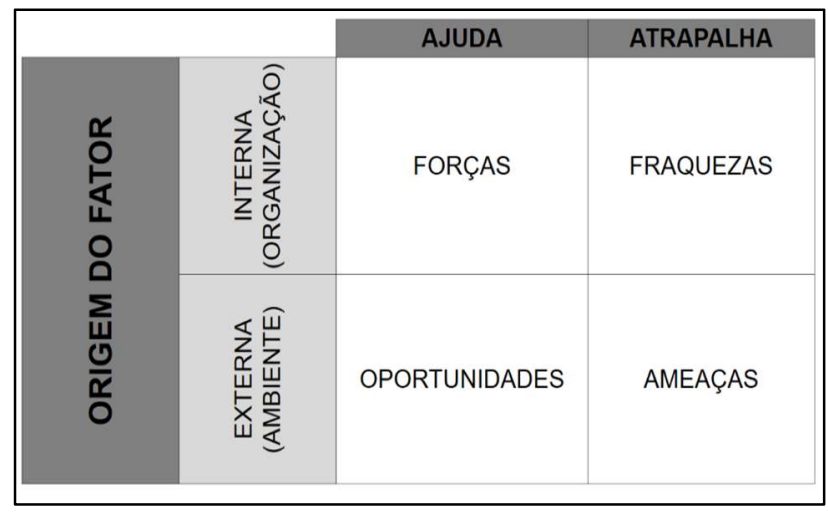

Figura 2: Análise SWOT. Fonte: Feil et al. (2012).

A análise do ambiente interno é importante, uma vez que ela permite a atividade turística verificar quais as forças e fraquezas, e como pode obter vantagem competitiva utilizando e potencializando suas forças para aumentar participação de mercado, elaborando estratégias para minimizar ou até mesmo eliminar suas fraquezas. $\mathrm{O}$ ambiente interno pode ser controlado, diferente do ambiente externo que não se 
tem o controle por parte da organização, mas ainda assim, a atividade turística pode controlar, conhecer com frequência, absorvendo as oportunidades e evitando as ameaças. Durante a pesquisa coletou-se dados e informações associando a Matriz SWOT, descrevendo as forças, as fraquezas, as oportunidades e as ameaças encontradas no local.

\section{RESULTADOS E DISCUSSÃO}

Para a elaboração da matriz SWOT foi necessário o estabelecimento dos parâmetros observados na comunidade durante a realização da pesquisa, para posterior análise entre forças, oportunidades, fraquezas e ameaças. No eixo horizontal do quadro 1, posicionaram-se as forças e fraquezas; já no eixo vertical, as oportunidades e ameaças. A partir daí, houve a correlação entre as áreas (sociais, ambientais e econômicas). Os principais aspectos identificados são apresentados no quadro 1.

Quadro 1: Análise do ambiente interno e externo da comunidade de Ponta de Pedras.

\begin{tabular}{|c|c|}
\hline FORÇAS & FRAQUEZAS \\
\hline $\begin{array}{l}\text { Atrativos naturais; } \\
\text { Existência de áreas propícias a trilhas } \\
\text { ecológicas; } \\
\text { Diversidade de fauna e flora; } \\
\text { Organização de comunitários; } \\
\text { Gastronomia; } \\
\text { Tranquilidade; e } \\
\text { Atrativos Culturais. }\end{array}$ & $\begin{array}{l}\text { Ausência de manutenção da estrada; } \\
\text { Carência de transporte público; } \\
\text { Descarte inapropriado de Resíduo; } \\
\text { Informações sobre os pontos turísticos inexistentes; } \\
\text { Deficiência de placas de sensibilização ambiental e de informações em outros } \\
\text { idiomas; } \\
\text { Ausência de banheiros químicos públicos; } \\
\text { Preços mais acessíveis na alimentação; } \\
\text { Precário atendimento ao público; } \\
\text { Segurança para os banhistas; e } \\
\text { Carência de unidade básica de saúde. }\end{array}$ \\
\hline OPORTUNIDADES & AMEAÇAS \\
\hline $\begin{array}{l}\text { Divulgação do local; } \\
\text { Ecoturismo; } \\
\text { Valorização Cultural; } \\
\text { Aumento da renda local; } \\
\text { Potencialidades para novos segmentos } \\
\text { turísticos; } \\
\text { Sistema efetivo de segurança e saúde; } \\
\text { Itinerário Turístico. }\end{array}$ & $\begin{array}{l}\text { Desmatamento de grandes áreas; } \\
\text { Atropelamento de fauna; } \\
\text { Expansão demográfica local; e } \\
\text { Propensão à violência e prostituição. }\end{array}$ \\
\hline
\end{tabular}

\section{Fragilidades da Comunidade Ponta de Pedras}

A ausência de manutenção das estradas na comunidade, incluindo a praia, foi um dos primeiros pontos observados durante a realização da pesquisa. Esse fator também foi relatado por diversos turistas e moradores locais, o que consequentemente desestimula novos investimentos no local e proporciona redução no número de turistas e visitantes. Para Costa et al. (2017), pontos turísticos com estradas de infraestruturas precárias afastam os turistas, pois dificultam o acesso ao local e a maior permanência dos turistas, é necessário que sejam feitos maiores investimentos nas vias de acesso.

Outro problema identificado é a dificuldade de informações a respeito do local, dos pontos turísticos existentes em Ponta de Pedras e a deficiência na disponibilidade de transporte público, uma vez que existe apenas uma linha de ônibus, somente no domingo e com um único horário de chegada e partida para o percurso praia-centro de Santarém/centro de Santarém-praia. 
Observou-se, na área, ausência de placas de educação ambiental e coletores de coleta seletiva, para que as atividades turísticas aconteçam de maneira harmoniosa, principalmente quando se trata de um lugar distante de centros urbanos como Ponte de Pedras. É necessária a existência de elementos da educação ambiental, não apenas para a manutenção da natureza, mas também como um atrativo turístico de responsabilidade sustentável com o meio ambiente.

Nesse sentido, um estudo realizado por Conto et al. (2009) mostrou que "há a necessidade de se disponibilizar informações aos hóspedes sobre o desenvolvimento de práticas ambientais nos meios de hospedagem, assim como do destino turístico, contribuindo com a sensibilização dos hóspedes sobre suas responsabilidades ambientais".

A pouca sinalização na estrada e o estado de conservação delas foi um dos aspectos diagnosticados, o que acaba gerando incidentes para quem não conhece o local, acarretando transtornos e reflete o baixo investimento em segurança das vias de acesso. Além de ausência de placas em outros idiomas que possam facilitar o acesso aos atrativos naturais existentes no local, existem apenas dois banheiros, um para cada gênero, que para serem utilizados, é necessário prévio pagamento para o responsável pela segurança e zelo do espaço.

Os valores excessivos de produtos e serviços foram registrados na pesquisa em campo. Além disso, foi destacada a falta de informações prévias disponíveis em mídias digitais, fato que inibe o conhecimento e consequentemente interesse em conhecer a região, retardando assim seu crescimento e desenvolvimento tanto econômico, quanto social.

Os restaurantes não apresentam estruturas básicas adequadas, ou seja, não possuem, por exemplo, banheiros e capacitação profissional de seus funcionários, e isso gera a sensação de descaso com as necessidades de seus clientes. A deficiência de saneamento básico, assim como, o mal armazenamento e acondicionamento de resíduos, além do fator estético, gera odores desagradáveis e aspectos de insalubridade do local, além de riscos à saúde humana, configurando um ambiente favorável a proliferação de vetores.

A ausência de caixas eletrônicos impossibilita a realização de transações financeiras, ou mesmo acesso a realização de pagamentos por serviços prestados na comunidade, reduzindo a comercialização de produtos e renda dos moradores. A falta de diferentes opções de pagamentos se dá pela indisponibilidade de aceitação de cartões eletrônicos, o que acaba limitando o pagamento dos serviços e produtos oferecidos pela comunidade apenas em espécie.

Observou-se também que a quantidade de lixeiras é insuficiente, estando um espaçamento entre as mesmas ao logo da praia muito distante, o que acaba contribuindo para o despejo em local impróprio do resíduo gerado, além da carência de cartazes contendo informações para o bom uso do ambiente, promovendo assim a sensibilização e a responsabilidade de zelo para os turistas/visitantes e comunitários. A comunidade possui déficit no sistema de comunicação, pois ela possui apenas uma operadora telefônica nacional em funcionamento instável e falta de internet banda larga para atender as necessidades de turistas/visitantes e comunitários. 
Outra fragilidade encontrada na área foi a precariedade do sistema de segurança, tanto no salvamento de banhistas, quanto no policiamento. Foi informado por moradores que a presença de órgãos de segurança pública só é notada no período de alta temporada, que ocorre nos meses de férias escolares e festividades da comunidade.

A comunidade Ponta de Pedra não possui nenhuma unidade básica de saúde presente em Ponta de Pedras; portanto, na ocorrência de incidentes, será necessário o deslocamento para a cidade de Santarém ou para Vila balneária de Alter-do-Chão, ambas com distância média de $25 \mathrm{~km}$. Os comunitários estão construindo com recursos próprios uma unidade básica de saúde, porém foi informado através da associação dos moradores que esta unidade ainda não possui data prevista para ser inaugurada.

\section{Oportunidades da Comunidade Ponta de Pedras}

A divulgação da comunidade em diferentes mídias sociais e digitais possibilitará o conhecimento e repercussão positiva sobre o lugar, despertando interesse e curiosidade em conhecer os aspectos encontrados que são poucos divulgados. Diante das novas modernidades, as pessoas buscam informações sobre um determinado local pela internet, que se tornou muito mais que um canal de comunicação, transformou-se em um mercado virtual para qualquer empresa e tipo de negócio. No âmbito do turismo, esta tecnologia é aliada no sentido de permitir a principal fonte de consulta a respeito dos destinos turísticos, atrativos e possibilidades de empresas e serviços necessários para organização de uma viagem. Desta forma, é necessário que os empreendimentos turísticos disponham informações prévias a respeito do destino turístico (BRAGA, 2008; CANDIOTO, 2012).

Outro ponto é o ecoturismo, uma vez que o ambiente está intimamente ligado com a natureza, oferecendo oportunidade de conhecimento da abundante vegetação situada no sistema. Ponta de Pedras possui o ambiente propício para o desenvolvimento de esportes de aventura, tornando-se um atrativo em particular para os praticantes dessa modalidade esportiva. Com a implantação de um sistema permanente de segurança seriam beneficiados visitantes/turistas e comunidade, resultando em maior confiabilidade e retorno econômico, dessa forma, o coletivo seria assistido, gerando uma qualidade de vida nos atores envolvidos sendo todos impactados positivamente.

O investimento em turismo propicia a expansão da economia local, gerando renda para os comunitários e empresários locais, além de contribuir para investimentos na própria região, como pavimentação de estrada, investimento em saneamento, capacitação de mão-de-obra, melhoria da infraestrutura para pessoas com necessidades especiais.

A valorização cultural é estimulada, sendo que se torna um atrativo turístico para os visitantes/turistas que procuram entretenimento local e conhecimento sobre a região. Outra oportunidade identificada é a implantação de hostels, que forneceria opções para a rede hoteleira local, gerando renda para os comunitários e melhoria na infraestrutura.

A redução de vetores de doenças pode ocorrer com a implantação de um sistema de saneamento eficaz que contemple toda a comunidade e considere os períodos mais intensos de fluxo de visitantes ou 
turistas. A oportunidade de planejamento de eventos pontuais em diferentes períodos do ano torna-se tradição e um atrativo a mais, e proporcionaria melhor equilíbrio da renda local.

A comunidade possui diferentes atrativos turísticos (praias, lago, áreas de floresta densa e savana, restaurantes com comidas típicas, festival do charutinho, áreas de encosta, as pedras que surgem no período de seca do Rio Tapajós, artesanatos, dentre outros). Estes precisam ser planejados e executados de acordo com o conceito de turismo sustentável propostos por Dias (2008) e Queiroz (2006). Na área, existe potencial para o turismo de praia e sol, turismo de aventura e ecoturismo. A elaboração de um itinerário turístico proporcionaria um roteiro com os principais pontos da localidade de Ponta de Pedras, seus atributos e belezas, repassando um sistema de organização efetivo para os visitantes e turistas, gerando renda para a comunidade que dispõe de guias turísticos para tal prática.

Segundo Beni (1999) há uma troca entre fatores de oferta e de demanda contínua, onde a demanda corresponde aos mercados de turismo internacional e domésticos, já os fatores de oferta agregam o produto, ou seja, os atrativos e atividades turísticas, alojamentos e outros equipamentos e serviços. Para que essa troca seja efetiva é necessário primeiramente o aprimoramento do produto ofertado, resultando em qualidade e consequentemente retorno ao local, como nas alternativas dispostas à comunidade.

\section{Forças da Comunidade Ponta de Pedras}

Cursos de gestão ambiental e turismo presentes na região se caracterizam como fomento de formação técnica para atividades vinculadas ao turismo, agregando o conhecimento técnico ao tradicional. A observação da rica cultura popular existente na comunidade de Ponta de Pedras mostrou-se um atrativo, que se estimulado, resultará em retorno turístico, gerando renda para os habitantes e fortalecendo os costumes locais.

O clima da região é extremamente favorável para o turismo de praia e sol, e assim, torna-se ponto alto para quem busca esse tipo de atração. Também ressalta a diversidade de ecossistemas representados por amplas áreas de florestas secundárias, área de vegetação alagada e savanas, além da diversidade de fauna e flora presentes.

A culinária local, bastante tradicional e principalmente conhecida em eventos como o Festival do charutinho (peixe pequeno muito apreciado na região) propicia boas experiências para quem visita; tornase, em muitos casos o motivo do retorno. As associações organizadas, tanto de restaurantes quanto de moradores, apresentam-se bem definidas e apresentam o mesmo objetivo: crescimento do turismo para comunidade.

Ponta de Pedras possui organização através da associação de trabalhadores das barracas que atendem os turistas na praia. Ressalta-se a importância da comunidade para o alcance dos objetivos e da promoção do turismo sustentável, para Beni (2006) a intervenção pública deve ser uma intervenção social participativa, ou seja, com a participação organizada das comunidades beneficiárias e outros atores sociais pertinentes. Logo, dentre outros, a organização da comunidade é um requisito para a participação e construção da sustentabilidade do processo. 
Outro ponto forte é a hospitalidade local que foi bem vista pelos turistas. Porém, fazem-se necessário cursos de capacitação para melhor atender as demandas de quem frequenta a área, uma vez que boa parte dos funcionários dos estabelecimentos não possuem capacitação para atendimento ao cliente e isso pode resultar para que o turista não retorne ou indique o local para outros.

De acordo com Melo (2011) “em um local que possui turismo em grande escala, é necessário haver uma mão-de-obra especializada, a fim de que o cliente seja bem servido, garantindo o seu retorno ou a propaganda positiva para que outras pessoas possam voltar". Melo (2011) também ressalta a importância de o órgão público municipal manter parcerias com entidades para a promoção de atividades qualificatórias dos trabalhadores do setor turístico, incluindo a população local.

\section{Ameaças ao sistema turístico da Comunidade Ponta de Pedras}

O desmatamento decorrente do crescimento turístico ocorre pela expansão da área de ocupação, que segue em direção as áreas de vegetação e é motivado pela construção de trilhas irregulares, além de expansão das estradas de acesso, a qual poderá aumentar os índices de atropelamento de fauna. O intenso fluxo de veículos também proporciona afugentamento da fauna, devido à poluição sonora, e fomenta a poluição atmosférica.

Para que ocorra o desenvolvimento turístico da comunidade de forma menos impactante ao ambiente natural, é necessário que as atividades sejam realizadas alinhadas a práticas sustentáveis e promova dessa forma o desenvolvimento de forma compatível com a conservação dos ambientes naturais. Para Klein et al. (2011):

[...] Embora o trânsito de pessoas e transportes possa ser impactante aos ecossistemas, é possível que a prática do ecoturismo contribua para a preservação dos mesmos quando aliada com a educação ambiental, podendo auxiliar no processo de desenvolvimento sustentável do local (...) admite-se que a educação ambiental está ligada à prática do ecoturismo assim como o ecoturismo está ligado a fatores de desenvolvimento sustentável que necessitam de planejamento, gestão e uma política considerada de alcance para os setores governamentais, as representações da sociedade civil e à iniciativa privada.

Outra ameaça é o aumento da prostituição e da violência, uma vez que, em lugares com alto fluxo turístico tais aspectos são frequentes. A falta de planejamento é outra ameaça que está relacionada com todos os demais riscos. A atividade turística quando planejada não abre oportunidades para ocorrências negativas diversas dentro da comunidade.

A descaracterização cultural também é uma ameaça que pode ocorrer na área e gerar a perda gradativa de costumes antes executados pelos povos tradicionais e inserção de novos hábitos, resultando em perda de sua identidade. A ausência de um sistema de saneamento eficiente e eficaz em conjunto com a geração de resíduos e rejeitos, principalmente em períodos de alta temporada também foi considerada uma ameaça para o sistema turística da comunidade.

O poder público é responsável pela instalação e manutenção dos diferentes equipamentos e serviços públicos citados anteriormente e que estão associados às fraquezas e ameaças do sistema turístico da comunidade Ponta de Pedras. Assim, para que o turismo sustentável ocorra nessa área, é necessária a presença efetiva do poder público. Nesse sentido, Barroco (2010) relata que a sustentabilidade turística 
apresenta um conjunto de dimensões (social, econômica, ambiental, cultural e tecnológica), devendo ser entendida pelos gestores como um processo social capaz de promover a integralidade do meio ambiente físico e cultural, a inserção dos membros da comunidade aos benefícios adquiridos pelo turismo, a qualidade dos produtos e serviços, e a otimização da experiência dos visitantes.

\section{CONCLUSÕES}

Após a análise de SWOT, foi possível definir as potencialidades da comunidade Ponta de Pedras e os grandes impasses para que se tenha um desenvolvimento turístico sustentável na área. A comunidade assim como possui grande potencial turístico, pois apresenta belezas naturais ímpares que são apreciadas por muitos turistas.

Através do diagnóstico, foi possível verificar que o local tem grande potencial não somente para o turismo de praia e sol, mas também de turismo de aventura e o ecoturismo que atualmente na região é pouco utilizado. Uma vez que, com o investimento necessário e planejamento poderiam expandir o desenvolvimento local e por consequência melhorar a qualidade de vida da população.

Em relação aos pontos negativos, verificou-se a falta de requisitos básicos como saneamento básico, serviços de saúde, educação e outros. Os poucos serviços e infraestrutura disponíveis são precários ou insistentes. Foi possível observar que a falta de planejamento e o descaso em relação ao investimento para o turismo na comunidade limita o desenvolvimento turístico local. Espera-se que os resultados apresentados contribuam com futuras estratégias para a promoção do desenvolvimento local de forma sustentável e com planos turísticos para que possa desenvolver o turismo e a economia da comunidade.

\section{REFERÊNCIAS}

ABREU, I. B.; COSTA, S. R.. Planejamento participativo e sua contribuição para desenvolvimento sustentável da atividade turística. In: SIMPÓSIO DE EXCELÊNCIA E GESTÃO E TECNOLOGIA, 11. Anais. Rio de Janeiro: AEDB, 2014.

ANCíN, J. M. S. V.. El plan de marketing en la práctica. 10 ed. Madrid: Esic, 2006.

ANDION, M. C.; FAVA, R.. Gestão empresarial. Curitiba: FA, 2002.

BARRETTO, M.. Planejamento responsável do turismo. Campinas: Papirus, 2005.

BARROCO, H.. Planejamento e Gestão: vetores para um turismo competitivo e sustentável. In: SEMINÁRIO DE PESQUISA EM TURISMO DO MERCOSUL, 6. Anais. Caxias do Sul: UCS, 2010.

BENI, M. C.. Política e estratégia do desenvolvimento regional: planejamento integrado e sustentável do turismo. Revista Turismo em Análise, São Paulo, v.10, n.1, p.7-17, 1999. DOI: http://doi.org/10.11606/issn.1984-4867.v10i1p7$\underline{17}$

BENI, M. C.. Política e planejamento estratégico no desenvolvimento sustentável do turismo. Revista Turismo em Análise, São Paulo, v.17, n.1, p.5-22, 2006.

DOI: http://dx.doi.org/10.11606/issn.1984-4867.v17i1p5-22

BIGNÉ, J.; FONT, X.; ANDREU, L.. Marketing de destinos turísticos: análisis y estrategias de desarrollo. Madrid: Esic, 2000.

BRAGA, D. C.. Agências de viagens e turismo: práticas de mercado. Rio de Janeiro: Elsevier, 2008.

BRAGA, D. C.. Planejamento turístico. Rio de Janeiro: Elsevier, 2013.

BRASIL. Plano Nacional de Turismo: 2018- 2022: mais emprego e renda para o Brasil. Brasília: MTur, 2018.

CANDIOTO, M. F.. Agências de Turismo no Brasil: embarque imediato pelo portão dos desafios. Rio de Janeiro: Elsevier, 2012.

CONTO, S. M.; ALVES, T. J. C.; PISTORELLO, J.; ZARO, M.; PESSIN, R.. Informações de hóspedes sobre gerenciamento de resíduos sólidos como fator decisivo na escolha do destino turístico. In: SEMINÁRIO DA ASSOCIAÇÃO BRASILEIRA DE PESQUISA E PÓS-GRADUAÇÃO EM TURISMO, 6. Anais. São Paulo: UAM, 2009. 
COSTA, D. N.; MELO, S. D.; PIMENTA, M. L.. Turismo e trabalho em pequenas cidades. Revista Rosas dos Ventos Turismo e Hospitalidade, Caxias do Sul, v.9, n.2, p.228-244, 2017. DOI: http://doi.org/10.18226/21789061.v9i2p228

CHAGAS, M. M.; SAMPAIO, L. M. B.; SANTOS, K. E. B.. Análise da influência da imagem de destinos na satisfação e fidelidade a destinações de turismo de sol e praia: um estudo em Natal/RN. Revista Brasileira de Pesquisa em Turismo, São Paulo, v.7, n.2, p.296-316, 2013. DOI: http://doi.org/10.7784/rbtur.v7i2.640

DANTAS, N. G. S.; MELO, R. S.. O método de análise SWOT como ferramenta para promover o diagnóstico turístico de um local: o caso do município de Itabaiana/PB. Caderno Virtual de Turismo, Rio de Janeiro, v.8, n.1, p.118-130, 2008

DIAS, R.. Turismo Sustentável e Meio Ambiente: Relação Turismo e Natureza. São Paulo: Atlas, 2008.

EMBRAPA. Empresa Brasileira de Pesquisa Agropecuária. Zoneamento ecológico-econômico da zona oeste do estado do Pará. Belém: EMBRAPA, 2010.

EMBRAPA. Empresa Brasileira de Pesquisa Agropecuária. Caracterização da área de estudo: ZEE BR-163. Belém: CPATU, 2014.

FEITOSA, M. A. C.; G.M. JULIÃO, M. D. P.; COSTA, B.; BELÉM, F. A. C.. Diversity of sand flies in domiciliary environment of Santarém, state of Pará, Brazil: species composition and abundance patterns in rural and urban areas. Acta Amazônica, Manaus, v.42, n.4, p.507-514, 2012. Dol: http://doi.org/10.1590/S0044-59672012000400008

FEIL, A. A.; HEINRINCH, A.. Aplicação da análise da Matriz SWOT em 5 agências de atendimento de uma cooperativa de crédito situada no Vale do Taquari-RS. Revista Eletrônica de Administração, v.11, n.1, 2012.

KLEIN, F. M.; ESCANDOLHERO, J. P. O.; LUCCHESE, N. R.; MERCANTE, M. A.; FÁVERO, S.; RODRIGUES, S. C.. Educação ambiental e o ecoturismo na Serra da Bodoquena em Mato Grosso do Sul. Revista Sociedade \& Natureza, Uberlândia, v.23, n.2, p.311-321, 2011. DOI: http://doi.org/10.1590/S1982-45132011000200013
LIMA, P. C. S.. Desenvolvimento local e turismo no Pólo de Porto de Galinhas - PE. Dissertação (Mestrado em Arquitetura e Urbanismo) - Universidade de Brasília, Brasília, 2006.

MARIANI, M. P.; DIAS, S. A.; SILVA, F. G.. Turismo e desenvolvimento local da comunidade de Ponta de Pedras/PA: a busca pela sustentabilidade. In: CONGRESSO DA SOCIEDADE BRASILEIRA DE ECONOMIA, ADMINISTRAÇÃO E SOCIOLOGIA RURAL, 46. Anais. Rio Branco: 2008.

MELO, N. R.. A aplicação da análise SWOT no planejamento turístico de uma localidade: o caso de Araxá, MG. Caderno Virtual de Turismo, Rio de Janeiro, v.11, n.2, p.164-176, 2011.

OMT. Organização Mundial do Turismo. Crónicas del turismo: el desarrollo comunitario sobre el terreno. Madrid: OMT, 2014

PARRA FILHO; D.; SANTOS, J. A.. Metodologia científica. 6 ed. São Paulo: Futura, 2003.

PEREIRA, L. N.. Morfologia urbana e atratividade de destinações turísticas: a importância da imagem na compreensão do sistema turístico da Vila de Alter do Chão. Dissertação (Mestrado em Turismo e Hoteleiro) Universidade do Vale do Itajaí, Santa Catarina, 2007.

PUTZ, F. E.; REDFORD, H. K.. Tropical forest definitions, degradation, phase shifts, and further transitions. Biotropica, v.42, p.10-20, 2010. DOI: https://doi.org/10.1111/j.17447429.2009.00567.x

QUEIROZ, O. T. M. M.. Turismo e Ambiente: temas emergentes. São Paulo: Alínea, 2006.

RODRIGUES, J. N.. $\mathbf{5 0}$ gurus para o século XXI. Lisboa: Centro Atlântico, 2005.

SILVA, M. A.; NEVES, R. J.; NEVES, S. M. A. S.. Possibilidades de incorporação do processamento do cumbaru do assentamento Facão, Furna São José, na cadeia produtiva do turismo rural: estudo de caso na fronteira Brasil/Bolívia. Revista Interações, Campo Grande, v.17, n.4, p.591-605, 2016. DOI: http://doi.org/10.20435/1984-042

A CBPC - Companhia Brasileira de Produção Científica (CNPJ: 11.221.422/0001-03) detém os direitos materiais desta publicação. Os direitos referem-se à publicação do trabalho em qualquer parte do mundo, incluindo os direitos às renovações, expansões e disseminações da contribuição, bem como outros direitos subsidiários. Todos os trabalhos publicados eletronicamente poderão posteriormente ser publicados em coletâneas impressas sob coordenação da Sustenere Publishing, da Companhia Brasileira de Produção Científica e seus parceiros autorizados. Os (as) autores (as) posteriormente ser publicados em coletâneas impressas sob coordenação da Sustenere Publishing, da Companhia Brasileira de Produção Científica e seus parce
preservam os direitos autorais, mas não têm permissão para a publicação da contribuição em outro meio, impresso ou digital, em português ou em tradução. 